\title{
Sorption Rate of Carbon Dioxide on Coal
}

\author{
Marek Gawor • Norbert Skoczylas
}

Received: 3 June 2013 / Accepted: 28 October 2013 / Published online: 14 November 2013

(C) The Author(s) 2013. This article is published with open access at Springerlink.com

\begin{abstract}
Traditionally, physicochemical processes whose result is the release of methane from a coal sample - often referred to as desorption - are discussed in relation to two phenomena, i.e., the transportation of gas inward (or outward) the porous substance, and the desorption (or sorption) proper of gas from the coal surface. The complex pore structure of coal necessitated the adoption of an arbitrary division of the gas transportation into: the diffusion of gas within the pore network in grains (understood as a molecular phenomenon) and the filtration of gas through the system of fissures and large pores (understood as a phenomenon related to the fluid mechanics). The filtration-type transportation of gas through a porous medium is most typically discussed in the context of the flow of gas through coal beds, or other porous rocks. In laboratory analyses carried out on granular samples obtained from the porous material, the filtrational flow of gas among the sorbent grains and within the fissure system is so fast (as compared to the diffusion occurring inside the grains) that the decisive factor influencing the kinetics of gas release is, most often, diffusion. In the case of such observations, it is assumed that the process of the sorption proper is almost instantaneous in its nature. There are no theoretical premises that would challenge an assumption thus formed, however, it would be very interesting to carry out an experiment confirming their existence. The present paper discusses an attempt to estimate, under laboratory conditions, the kinetics of the sorption proper. It provides a description of the specially built measuring equipment, as well as the results of the performed experiments, together with their analysis. In the performed experiments, the obtained time constants of sorption were smaller than $50 \mathrm{~ms}$. The lowest values did not exceed $10 \mathrm{~ms}$. Since the obtained time constant values are very low-in spite of the fact that it was impossible to completely eliminate the delays connected with the transportation of molecules to the sorption sites - the authors are of the opinion that the process of sorption proper shall be assumed to be instantaneous.
\end{abstract}

M. Gawor · N. Skoczylas $(\varangle)$

Strata Mechanics Research Institute of the Polish Academy of Sciences, Kraców, Poland e-mail: skoczyla@img-pan.krakow.pl http://www.img-pan.krakow.pl

M. Gawor

e-mail: gawor@img-pan.krakow.pl 
Keywords Gas flow $\cdot$ Diffusion $\cdot$ Sorption $\cdot$ Sorption rate

\section{Introduction}

It is frequently the case that, when the release of the sorbate from the sorbent is discussed, the idea of "desorption" is used in a broader sense than it would issue from the very nature of the process. Thus, "desorption" means a number of processes resulting in the release of the sorbing gas from the sorbent. When speaking about the release of methane from a coal bed into an excavation, we typically mean the combination of the filtration (Crank 1975; Timofejew 1967; Pillalamarry et al. 2011; Hu et al. 2009; Wu et al. 1998), diffusion, and sorption processes, which will further be referred to as "the sorption proper" (Harpalani and Chen 1997; Pillalamarry et al. 2011; Day and Sakurovs 2008; Weniger et al. 2010; CeglarskaStefańska and Zarębska 2005; Majewska et al. 2009; Busch and Gensterblum 2011; Nagaoka and Imae 2003). Under laboratory conditions, in which case the investigations are carried out for small-sized grain samples, we can assume that the transportation of gas is influenced mainly by the diffusion processes. The kinetic aspects of the diffusion and filtration processes have been studied and described quite thoroughly (Alexeev et al. 2010, King and Ertekin 1989a,b, Harpalani and Schraufnagel 1990a,b; Crosdale and Beamish 1998; Li et al. 2012). The methods of determining the diffusion coefficient and the material permeability coefficient have also been mastered. The factors that have an impact on the speed of these processes are well known. However, in relevant sources, the notion of "sorption kinetics" is often used to refer to the speed of the filtration and diffusion processes (Kawęcka 1988; Busch et al. 2004; Wierzbicki 2011). Most studies neglect the aspects of the kinetics of the sorption proper, as their main focus is on the steady states, or the issues related to the gas transportation. Their authors make an explicit or implicit assumption that the sorption itself is instantaneous (Clarkson and Bustin 1999). When it comes to assessing the speed of the sorption proper, the biggest difficulty lies in developing such a measuring methodology that would minimize, as effectively as possible, the impact of gas transportation upon the measurement results.

\section{Determining the Time Constant of the Sorption Proper of Gas on Hard Coal}

The basic assumption of the developed measurement methodology for determining the speed of the processes of the sorption proper was to minimize the impact of the effects related to gas transportation. Therefore, the sorption heat effects were used, which will serve as a basis for inferences about the speed of the sorption process. These effects are connected with the energy of the interaction between a gas particle and the surface of a solid material (Ecknauer et al. 1981). If a gas particle is adsorbed on the surface of a solid material, the sorption heat $Q_{\mathrm{s}}$ is immediately released. During the desorption process, the heat is absorbed from the environment and the carbon skeleton, which is why the coal cools down (Timofejew 1967). Therefore, we shall assume that the speed of the heat release during sorption processes is the measure of the speed with which the sorption process itself occurs. Thus, by measuring the temperature changes during that process, we are able to determine the time constant of sorption $-\tau_{\mathrm{s}}$. When doing that, one should make sure that the size of the coal grains dusted onto the thermometer is as small as possible, and that there is only one layer of grains. If we take account of the fact that, in this experiment, it is not possible to totally eliminate the processes of gas transportation, we can assume (having taken into consideration the fact that transportation of gas is not accompanied by any heat effects) that the chosen method of 
measuring the sorption time constant is not dependent on the size of the grains used in the experiment.

\subsection{The Measuring Position}

The general idea of the investigations discussed here is to carry out a temporal analysis of the changes in the temperature indicated by a thermometer coated with a layer of coal. The thermometer is placed within a stream of argon, and then within a stream of carbon dioxide, alternately. A schematic drawing of the measuring equipment is presented in Fig. 1. Argon and carbon dioxide flow into a measuring chamber, passing through a reducer, a flow meter, and a system for stabilizing the temperature of the gases. Both gas streams have the same temperature. The measuring chamber consists of two pipes connected at the end section, at a slight angle. Close to the meeting point of the pipes supplying argon and carbon dioxide, a special mechanism is installed, which makes it possible to move the coal-coated thermometer between the two gas streams in a possibly fastest way. The time period needed for moving the thermometer is ca. $20 \mathrm{~ms}$.

In order to measure the changes in temperature during sorption and desorption of carbon dioxide on hard coal, resistance thermometers were used. A sensor was made out of a Pt-Rh resistance wire with the outlet diameter of $10 \mu \mathrm{m}$. After the wire had been flattened, sensors whose thickness was between 1 and $1.3 \mu \mathrm{m}$ were obtained. Due to its specific mechanical strength, it was impossible to flatten the wire further (which would ultimately result in decreasing its time constant). The time constant for resistance thermometers is ca. $5 \mathrm{~ms}$.

Thus constructed thermometer, which had been tested before the start of the experiment, was coated with coal grains whose size was between 4 and $26 \mu \mathrm{m}$. In order to ensure a better thermal contact, as well as a mechanical contact between the coal grains and the thermometer, the grains were glued to the thermometers with diluted nitro lacquer.

Fig. 1 Measuring the time constant of sorption

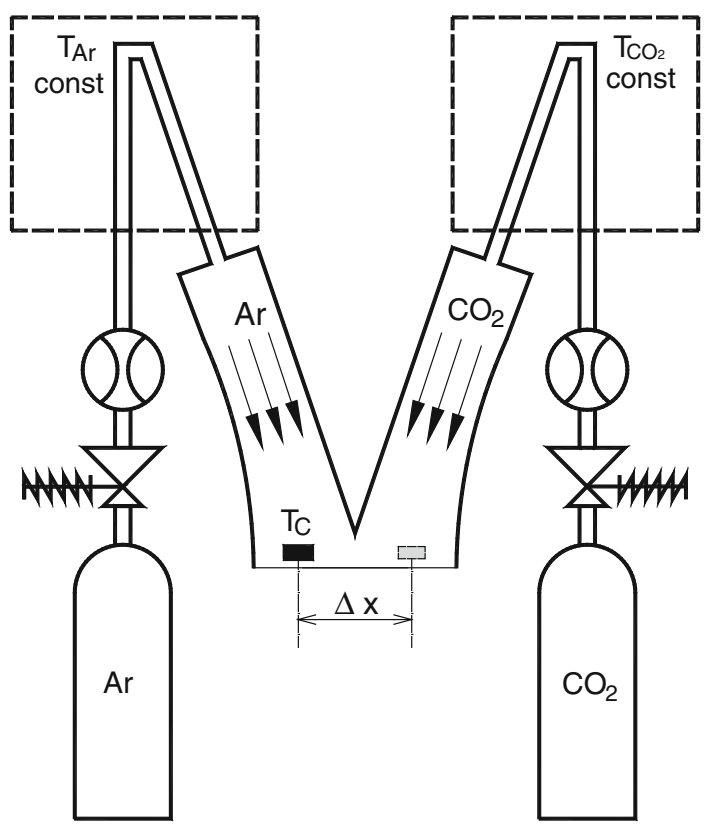


Table 1 Coal parameters

\begin{tabular}{lllllll}
\hline Ash $(\%)$ & $\begin{array}{l}\text { Moisture } \\
\text { content } \\
W^{\mathrm{A}}(\%)\end{array}$ & $\begin{array}{l}\text { Volatile matter } \\
\text { content } \\
V^{\text {daf }}(\%)\end{array}$ & $\begin{array}{l}\text { Carbon } \\
\text { content } \\
C^{\text {daf }}(\%)\end{array}$ & $\begin{array}{l}\text { True density } \\
d_{\mathrm{He}}\left(\mathrm{g} / \mathrm{cm}^{3}\right)\end{array}$ & $\begin{array}{l}\text { Apparent } \\
\text { density } \\
d_{\mathrm{Hg}}\left(\mathrm{g} / \mathrm{cm}^{3}\right)\end{array}$ & $\begin{array}{l}\text { Pore volume } \\
V_{\mathrm{p}}\left(\mathrm{cm}^{3} / \mathrm{g}\right)\end{array}$ \\
\hline 7.89 & 1.13 & 29.27 & 86.38 & 1.37 & 1.304 & 0.037 \\
\hline
\end{tabular}

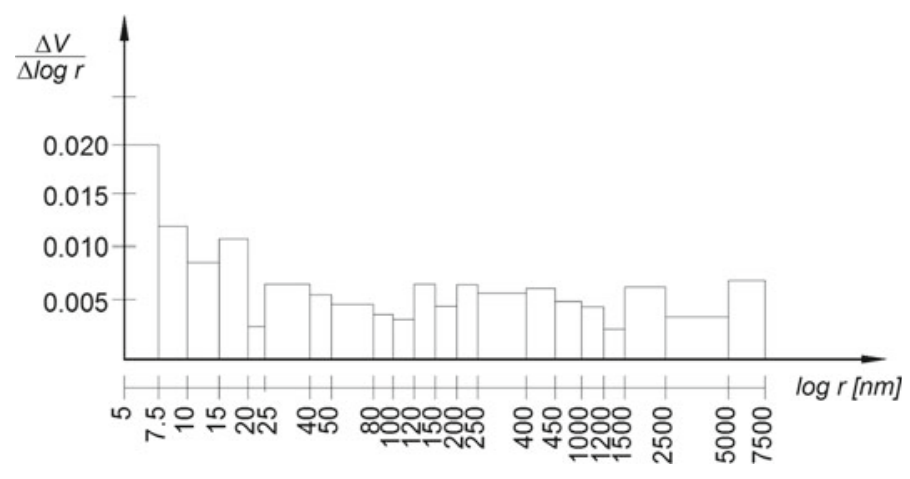

Fig. 2 The histogram of the differential distribution of the pore volume in relation to pore radii

A coal sample from "Thorez" coal mine facility, located in the Lower Silesian Coal Basin, Poland, is characterized by the following parameters (Nodzeński 1990) (Table 1).

The histogram of the differential distribution of the pore volume in relation to pore radii, for the investigated coal, is presented in Fig. 2.

The gases used in the experiment were carbon dioxide and argon, which have similar molecular masses (44 and 40, respectively). It was assumed that the sorption of argon on hard coal is quite low when compared to the sorption of carbon dioxide. The proper execution of the experiment excluded the usage of helium as an unsorbable gas due to the Dufour effect, which is a phenomenon opposite to thermodiffusion. During the mixing of two gases which have the same temperature and which do not react with each other (like helium and air), a temperature difference of several degrees is observed.

After the coal-coated thermometer had been moved from the stream of argon into the stream of carbon dioxide, the adsorption process would begin. As a result of the release of the sorption heat, the coal would get warmer, and, at the same time, cooled down by the gas stream. The temperature would rise to a certain value-and then drop to the initial value. When the coal-coated thermometer was moved in the opposite direction (i.e., from the stream of carbon dioxide into the stream of argon), changes in the temperature had an opposite symbol. During the desorption process, the coal would cool down, and then its temperature would rise to the initial value.

\subsection{The Heat Balance of the Coal-Coated Thermometer During the Gas Sorption Process}

In order to interprete the obtained results properly, it is essential to establish the heat conduction equation. Changes in the coal temperature are connected with the sorption effects, as well as with the heat being passed to the stream of gas. The heat balance can be described by means of the following equation: 


$$
\rho c_{\mathrm{p}} \frac{\partial T(t)}{\partial t}=-\alpha \beta\left(T(t)-T_{\mathrm{k}}\right)+q_{\mathrm{r}},
$$

where $t$ is the time (s), $T(t)$ is the temperature $(\mathrm{K}), q_{\mathrm{r}} \quad$ is the volumetric efficiency of the heat source, related to the gas sorption $\left(\frac{\mathrm{W}}{\mathrm{m}^{3}}\right), c_{\mathrm{p}}$ is the specific heat capacity for a constant pressure value $\left(\frac{\mathrm{J}}{\mathrm{kg} \mathrm{K}}\right), \rho$ is the density $\left(\frac{\mathrm{kg}}{\mathrm{m}^{3}}\right), \alpha$ is the heat-transfer coefficient $\left(\frac{\mathrm{W}}{\mathrm{K} \mathrm{m}^{2}}\right), \beta$ is the thermal absorption coefficient $\left(\mathrm{m}^{-1}\right)$, and $T_{\mathrm{k}}$ is the final temperature of the gas (the stream temperature) $(K)$.

The volumetric efficiency of the internal heat source, related to the sorption processes, is proportional to the heat of the sorption and the speed with which the changes in the adsorbed gas take place:

$$
q_{\mathrm{r}}(t)=Q_{\mathrm{s}} \frac{\partial a(t)}{\partial t},
$$

where $a(t)$ is the amount of the adsorbed gas at specific time $t$, expressed as the mass of the sorbed gas per unit of coal volume $\left(\frac{\mathrm{kg}}{\mathrm{m}^{3}}\right)$ and $Q_{\mathrm{s}}$ is the heat of the sorption $\left(\frac{\mathrm{J}}{\mathrm{kg}}\right)$.

The speed of the gas desorption is proportional to the difference between the amount of the adsorbed gas at specific time $a(t)$ and the amount of gas $a_{\mathrm{m}}$ that can be sorbed under given thermodynamic conditions, for specific pressure and temperature values, and after an infinite period of time (Kel'cev 1980). The equation of the sorption kinetics is as follows:

$$
\frac{\partial a(t)}{\partial t}=-\frac{1}{\tau_{\mathrm{s}}}\left(a(t)-a_{\mathrm{m}}\right),
$$

where $\tau_{\mathrm{s}}$ is the time constant of sorption (s).

Let us assume that, at the time $t=0$, the concentration of carbon dioxide is $c_{0}$. The corresponding (via the sorption isotherm) amount of the adsorbed gas is $a_{0}$. Subsequently, the concentration of the carbon dioxide assumes the value $c_{\mathrm{m}}$ in an infinitely fast way (the dislocation of the coal-coated thermometer), which, in a steady state, equals the amount of the adsorbed gas $a_{\mathrm{m}}$. For such initial conditions, Eq. (3) has the following solution:

$$
a(t)=\left(a_{0}-a_{\mathrm{m}}\right) \exp \left(-\frac{t}{\tau_{\mathrm{s}}}\right)+a_{\mathrm{m}}
$$

After supplying the solution of Eq. (3) into the Eq. (1), we arrive at the following formula:

$$
\frac{\partial T(t)}{\partial t}=-\frac{1}{\tau_{t}}\left(T(t)-T_{\mathrm{k}}\right)+\frac{Q_{\mathrm{s}}\left(a_{\mathrm{m}}-a_{0}\right)}{c_{\mathrm{c}} \tau_{\mathrm{s}}} \exp \left(-\frac{t}{\tau_{\mathrm{s}}}\right)
$$

If we consider a process during which adsorption does not occur-such as moving the coal-coated thermometer from one carbon dioxide stream to another carbon dioxide stream, whose temperature is slightly higher-the second term of Eq. (5) disappears. Equation (5) shows that the constant $\tau_{\mathrm{t}}$ can be interpreted as the time constant of the process of leveling the temperatures between the thermometer and the gas stream. Taking this into account, we are able to determine the time constant of the coal-coated thermometer.

Let us now consider the adsorption process, making an assumption that the thermometer with coal — at the initial moment—is placed within a stream of argon whose temperature is $T_{0}$, and then is moved into a stream of carbon dioxide whose temperature is $T_{\mathrm{k}}$. For such initial conditions, the solution of Eq. (5) takes the form of the following function:

$$
T(t)=A \exp \left(-\frac{t}{\tau_{\mathrm{s}}}\right)+B \exp \left(-\frac{t}{\tau_{t}}\right)+T_{\mathrm{k}},
$$


where

$$
\begin{aligned}
& A=\frac{Q_{\mathrm{s}}\left(a_{\mathrm{m}}-a_{0}\right)}{c_{\mathrm{c}}\left(\frac{\tau_{\mathrm{s}}}{\tau_{\mathrm{t}}}-1\right)}(\mathrm{K}) \\
& B=T_{0}-T_{\mathrm{k}}-A(\mathrm{~K})
\end{aligned}
$$

As can be seen from formula (6), the experiment involves two opposite processes characterized by different time constants. During the adsorption process, due to the heat release, the temperature of the thermometer with coal increases. The time constant of this process equals $\tau_{\mathrm{s}}$. At the same time, due to the difference between the temperatures of the gas stream and of the coal-coated thermometer, the leveling of temperature values takes place. The time constant of this process equals $\tau_{t}$.

The function $T(t)$ is a function with five unknown parameters: $A, B, \tau_{\mathrm{s}}, \tau$, and $\Delta T=$ $T_{0}-T_{\mathrm{k}}$. The data obtained in the course of the experiment was used to calculate the values of the parameters of this function. In order to do this, the following objective function was constructed:

$$
f\left(A, B, \tau_{\mathrm{s}}, \tau, \Delta T\right)=\sum_{i=1}^{n}\left[T\left(A, B, \tau_{\mathrm{s}}, \tau, \Delta T\right)-T_{i}\right]^{2},
$$

where $T_{i}$ is the temperature obtained during the experiment, at the moment $t_{i}(\mathrm{~K})$.

Subsequently, Powell's gradient method (Press et al. 1986) was used to determine the minimum of the function $f\left(A, B, \tau_{\mathrm{s}}, \tau, \Delta T\right)$. As a result, it was possible to establish the time constants of the sorption process, as well as of the temperature leveling process.

\subsection{The Experiment Results}

In order to determine the time constant of sorption, it is necessary to perform a speedy measurement of the changes in the temperature of the coal dusted onto the thermometer during the sorption process, induced by a change in the gas concentration. Prior to these investigations, tests were carried out to establish the parameters of the thermometers as such. A thermometer not coated with coal was moved from a stream of argon into another stream of argon, whose temperature was slightly different (subsequently, this sequence was reversed). In this case, we are dealing with the temperature-leveling process, described by means of Eq. (5) devoid of the last term, related to the gas sorption on coal. The quantity $\tau_{t}$ is the time constant of the temperature-leveling process. It provides information on how fast the thermometer reacts to a step change in temperature.

Obviously, the thinner the thermometer which measures the temperature changes, the shorter the time constant $\tau_{t}$. This is due to the change in the thermal capacity of the thermometer, which depends on its mass. The time constant of a $1.3-\mu \mathrm{m}$ thick resistance thermometer was ca. $5 \mathrm{~ms}$.

The time constant of the temperature-leveling process will change when the thermometer is covered with a layer of coal (the thermal capacity of the thermometer-coal system will change). Some experiments analogous to the ones described above were carried out, however, the thermometer was in that case covered with layers of coals of various thickness. Since both streams were the streams of the same gas, our experiments do not entail a heat exchange related to the gas sorption. For a $4-\mu \mathrm{m}$ thick thermometer and a $25-\mu \mathrm{m}$ thick layer of coal, the time constant of the temperature-leveling process is $120 \mathrm{~ms}$. For a $1.3-\mu \mathrm{m}$ thick thermometer and a $6.5-\mu \mathrm{m}$ thick layer of coal, it is $13 \mathrm{~ms}$. 


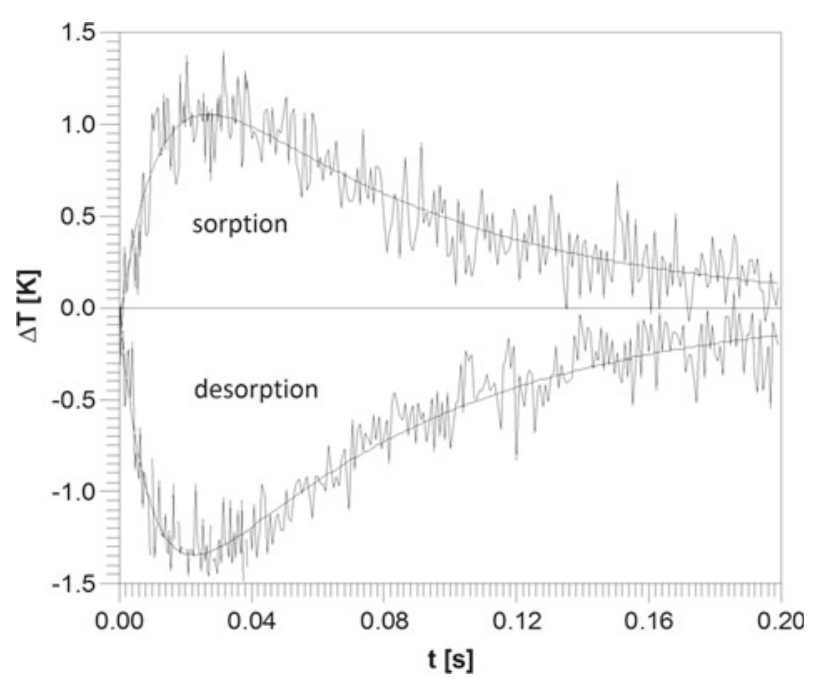

Fig. 3 A temperature change occurred during the measurements of the time constant of $\mathrm{CO}_{2}$ sorption and desorption

Figure 3 presents changes in the temperature registered while the coal-coated thermometer was moved from the stream of argon into the stream of carbon dioxide (adsorption), and from the stream of carbon dioxide into the stream of argon (desorption). The thin line in the diagrams below represents a theoretical curve, adjusted to the experiment data. On its basis, the time constants of the sorption and the temperature-leveling process were determined. Such diagrams, obtained in the course of experiments, served as a basis for determining the time constant of sorption.

The lowest time constant of sorption was obtained for a $1.3-\mu \mathrm{m}$ thick resistance thermometer, covered with a $6.5-\mu \mathrm{m}$ thick layer of coal. Its value was $10 \mathrm{~ms}$. However, for very thin layers of coal, the temperature changes were rather insignificant. Thus, the determined time constant of sorption might be characterized by a major measurement uncertainty. In most experiments, the time constant would not exceed $50 \mathrm{~ms}$. Therefore, it needs to be stated that the process of sorption itself is a very fast process.

\subsection{Potential Errors and Measurement Uncertainties}

In order to find out what is the influence of temperature and the thickness of a coal layer upon the time constant of sorption, experiments were carried out during the processes of carbon dioxide sorption and adsorption, for three different temperature values and three layers of coal of various thickness, put on the thermometer. Figures 4 and 5 show the results of the measurements of the sorption time constant, both during the adsorption and desorption process, in relation to the temperature of the sorbed gas.

The diagrams leave no doubt as to the actual impact of the thickness of the coal layer upon the value of the calculated time constant. The thicker the layer, the greater the value of the latter. This means that even with such thin layers of coal filtration processes play a decisive role when it comes to the speed with which sorption takes place. This becomes totally understandable once we compare the size of pores in which the transportation of gas occurs to the scope of the coal layer dusted onto the thermometer. Filtration takes place in 


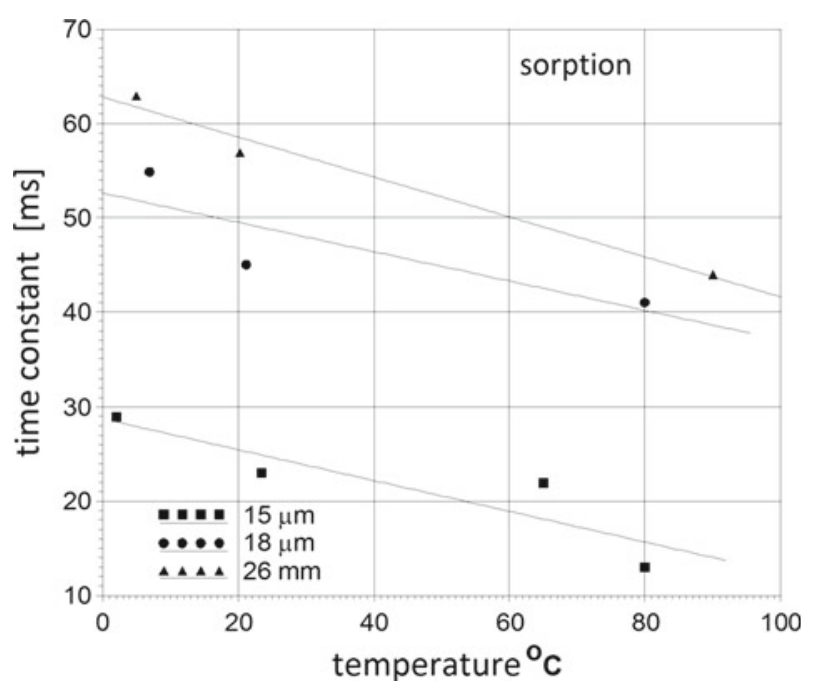

Fig. 4 The relationship between the adsorption time constant and temperature

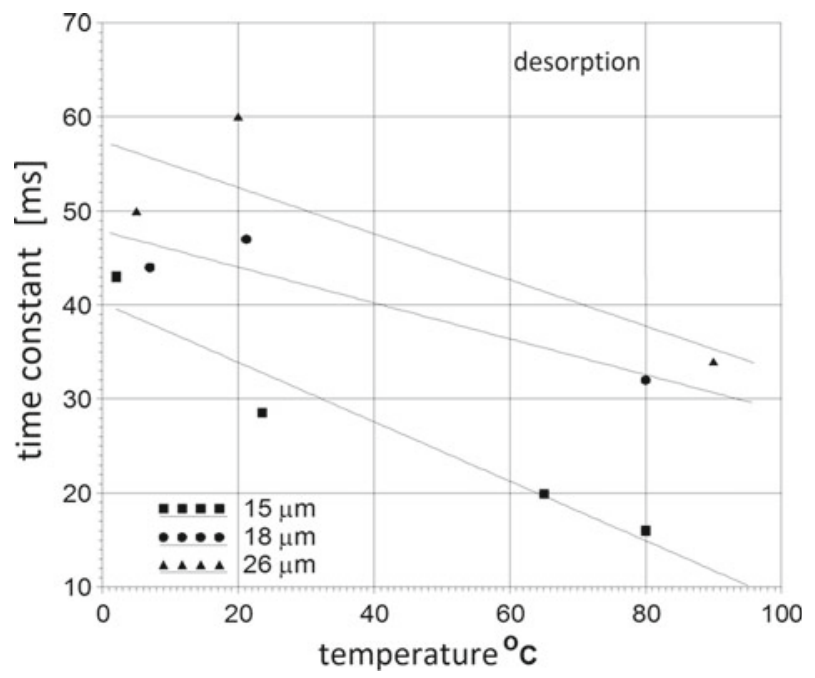

Fig. 5 The relationship between the desorption time constant and temperature

pores whose diameters are measured in nanometers, and the thickness of the coal layer is between 10 and $20 \mu \mathrm{m}$.

The speed with which sorption occurs on a smooth and energetically homogenous surface is determined by two opposing processes: the adherence of molecules on the surface as a result of the adhesion forces, and the transformation of the adsorbed particles into the gas phase due to the energy supplied by the thermal vibrations of the sorbent particles. For the sake of this argument, let us adopt the assumptions of the Langmuir theory. The adsorption process occurs on the surface on empty active sites, solely. There is no interaction between the sorbed particles. On each active site, only one particle can be adsorbed (monolayer adsorption). Only some of the particles falling to the surface of a solid material are adsorbed. 
With these assumptions, the equation of the sorption kinetics assumes the following form (Damköhler 1935):

$$
v_{0} \frac{\mathrm{d} \Theta}{\mathrm{d} t}=\alpha_{\mathrm{a}} \mu(1-\Theta)-v \Theta,
$$

where $\Theta$ is the extent to which a surface is covered with a monomolecular layer, expressed as the ratio of the number of adsorbed gas particles and the total number of particles that can be absorbed: $\Theta=a / a_{\mathrm{m}}, \mu$ is the number of particles falling to a unit of surface within a unit of time $\left(\frac{1}{\mathrm{~m}^{2} \mathrm{~s}}\right), v$ is the number of particles leaving a unit of surface within a unit of time $\left(\frac{1}{\mathrm{~m}^{2} \mathrm{~s}}\right), v_{0}$ is the number of particles falling on a unit of the sorbent's surface $\left(\frac{1}{\mathrm{~m}^{2}}\right)$, and $\alpha_{\mathrm{m}}$ is a non-dimensional accommodation coefficient, determining the probability of adsorption of a particle falling to the surface.

The solution to this equation, with the initial condition being $t=0 ; \Theta=\Theta_{0}$, is the following function:

$$
\Theta=\left(\Theta_{0}-\frac{\alpha_{\mathrm{a}} \mu}{\alpha_{\mathrm{a}} \mu+v}\right) \exp \left(-\frac{t}{\tau_{\mathrm{s}}}\right)+\frac{\alpha_{\mathrm{a}} \mu}{\alpha_{\mathrm{a}} \mu+v},
$$

where $\tau_{\mathrm{s}}$ is the time constant of sorption (s).

One can demonstrate that the dependence of the sorption time constant on temperature is as follows (Gawor 1993):

$$
\tau_{\mathrm{s}}=\tau_{0} \exp \left(\frac{Q_{\mathrm{m}}}{R T}\right)
$$

where $Q_{\mathrm{m}}$ is the molar heat of sorption $\left(\frac{\mathrm{J}}{\mathrm{mol}}\right), R$ is the universal gas constant $\left(\frac{\mathrm{J}}{\mathrm{mol} \mathrm{K}}\right)$, and $\tau_{o}$ is the constant not dependent on temperature (s).

Formula (10) brings us to the conclusion that the time constant of sorption gets shorter with an increase in temperature. As can be seen in Figs. 4 and 5, a similar tendency revealed by the time constant of sorption was observed during the discussed experiments.

\section{Conclusions}

Careful inspection of the sources quoted in the majority of scientific papers reveals that they do not differentiate between the kinetics of the sorption process and the transportation of gas on hard coal. In almost every experiment, the sorption kinetics is understood as the speed with which gas enters the porous structure of coal. However, from the perspective of physics, sorption and gas transportation are two completely different processes. Some models aiming at determining the kinetics of the sorption proper are introduced only as part of theoretical discussions. The authors of the present paper suggest that the applied terminology should better reflect a process under investigation (e.g., the diffusion kinetics).

A significant changeability of the sorption properties of coal means that it is difficult to compare the experiment results, even when the kinetic parameters are carefully defined. When the processes of sorption and filtration are viewed as two totally separate phenomena, one can assume that the speed of the sorption process is determined by the time constant defined by formula (3). This quantity does not depend on the size of grains and the distribution of the size of pores within grains. This is in accordance with the mechanism of the sorption process, which involves the interaction of forces between a gas particle and the atoms of the solid material surface. 
The performed experiments bring us to the conclusion that the time constant of sorption is definitely shorter than $50 \mathrm{~ms}$. This estimation is quite formal, as, when the experiments were carried out, it was impossible to totally eliminate the transportation-related processes.

While determining the time constant of sorption, the thickness of the coal layers was consistently reduced, until it was just a few micrometers. On the one hand, it made it possible to eliminate the impact of the transportation; on the other-it resulted in the reduction of the temperature signal and an increase in measurement uncertainty. Under such conditions, the obtained time constant of sorption was ca. $10 \mathrm{~ms}$.

The essential conclusion to be drawn from these experiments is that the sorption of gases on hard coal is a process much faster than the transportation of gas into the porous structure of coal. Therefore, in theoretical analyses of the kinetics of gas penetration into coal, one can neglect the terms related to the gas sorption, and assume that it occurs instantaneously.

In practical mining, the value of the time constant of sorption is quite irrelevant, which is due to the fact that non-stationary processes of the gas-coal interaction are inseparably linked to filtration and diffusion. The kinetics of the sorption process may be of vital importance only during the crushing of coal masses (and exposing new surfaces). A similar situation occurs during gas and rock outbursts, and crumps (Skoczylas 2012a,b).

Open Access This article is distributed under the terms of the Creative Commons Attribution License which permits any use, distribution, and reproduction in any medium, provided the original author(s) and the source are credited.

\section{References}

Alexeev, A.D., Feldman, E.P., Vasilenko, T.A.: Kinetics of methane desorption from coal nano and mesostructures. Energy Fuels 24(8), 4375-4379 (2010)

Busch, A., Gensterblum, Y.: $\mathrm{CBM}$ and $\mathrm{CO}_{2}-\mathrm{ECBM}$ related sorption processes in coal: a review. Int $\mathrm{J}$ Coal Geol 87(2), 49-71 (2011)

Busch, A., Gensterblum, Y., Krooss, B.M., Littke, L.: Methane and carbon dioxide adsorption-diffusion experiments on coal: upscaling and modeling. Int J Coal Geol 60(2-4), 151-168 (2004)

Ceglarska-Stefańska, G., Zarębska, K.: Sorption of carbon dioxide-methane mixtures. Int J Coal Geol 62(4), 211-222 (2005)

Clarkson, C.R., Bustin, R.M.: The effect of pore structure and gas pressure upon the transport properties of coal: a laboratory and modeling study. 2. Adsorption rate modeling. Fuel 78(11), 1345-1362 (1999)

Crank, J.: Mathematics of diffusion. Oxford University Press, London (1975)

Crosdale, P.J., Beamish, B.B., Valix, M.: Coalbed methane sorption related to coal composition. Int J Coal Geol 35, 147-158 (1998)

Damköhler G.: Z Phijs Chem (Frankfurt/Main) A174, 222 (1935).

Day, S., Sakurovs, R., Weir, S.: Supercritical gas sorption on moist coals. Int J Coal Geol 74(3-4), 203-214 (2008)

Ecknauer, R., Siricar, B., Johnson, L.R.: Effect of dietary bulk on small intestinal morphology and cell renewal in the rat. Gastroenterology 81, 781-786 (1981)

Gawor, M.: Sorption and diffusion of gases. Arch Min Sci 38(3), 217-261 (1993)

Hu, G., Wang, H., Fan, X., Yuan, Z., Hong, S.: Mathematical model of coalbed gas flow with Klinkenberg effects in multi-physical fields and its analytic solution. Transp Porous Med 76(3), 407-420 (2009)

Harpalani, S., Schraufnagel, R.A.: Measurement of parameters impacting methane recovery from coal seams. Int J Min Geol Eng 8, 369-384 (1990a)

Harpalani, S., Schraufnagel, R.A.: Shrinkage of coal matrix with release of gas and its impact on permeability of coal. Fuel 69, 551-556 (1990b)

Harpalani, S., Chen, G.: Influence of gas production induced volumetric strain on permeability of coal. Geotech Geol Eng 15, 303-325 (1997)

Kawęcka, J.: Sorpcja gazów i par a wł aściwości polskich węgli kamiennych jako układów dyspersyjnych, Zesz. Nauk. AGH, Chemia, z. 8 (1988). 
Kel'cev, N.V.: Fundamentals of adsorption, Scientific and Technical Publishing (1980)

King, G.R., Ertekin, T.M.: A survey of mathematical models related to methaneproduction from coal seams, Part 1. Empirical and equilibrium sorption models. Proc. 1989Coalbed Methane Symp. The University of Alabama, Tuscaloosa, pp. 125-138 (1989a)

King G.R., Ertekin T.M.: A survey of mathematical models related to methane production from coal seams, Part II: Nonequilibrium sorption models. Proc. 1989, Coalbed Methane Symp. The University of Alabama, Tuscaloosa, p. 139-155 (1989b)

Majewska, Z., Ceglarska-Stefańska, G., Majewski, S., Ziętek, J.: Binary gas sorption/desorption experiments on a bituminous coal: simultaneous measurements on sorption kinetics, volumetric strain and acoustic emission. Int J Coal Geol 77(1-2), 90-102 (2009)

Nagaoka, H., Imae, T.: Analytical investigation of two-step adsorption kinetics on surfaces. J Colloid Interface Sci 264(2), 335-342 (2003)

Nodzeński, A.: Nonisothermal desorption of carbon dioxide from coals with different texture, strata as multiphase medium, rock and gas outbursts. AGH Publisher, Kraców (1990)

Pillalamarry, M., Harpalani, S., Liu, S.: Gas diffusion behavior of coal and its impact on production from coalbed methane reservoirs. Int J Coal Geol 86, 342-348 (2011)

Press, W. H., Teukolsky, S. A., Vetterling, W. T., Flannery, B, P.: Preface. Numerical recipes: The art of scientific computing. Cambridge University Press, New York (1986). p. xi. ISBN 0-521-30811-9

Skoczylas, N.: Laboratory study of the phenomenon of methane and coal outburst. Int J Rock Mech \& Min Sci 55, 102-107 (2012a)

Skoczylas, N.: Coal seam methane pressure as a parameter determining the level of the outburst risk: laboratory and in situ research. Arch Min Sci 57, 819-830 (2012b)

Timofejew, D.: Adsorption kinetics, (1967)

Weniger, P., Kalkreuth, W., Busch, A., Krooss, B.M.: High-pressure methane and carbon dioxide sorption on coal and shale samples from the Paraná Basin, Brazil. Int J Coal Geol 84(3-4), 190-205 (2010)

Wierzbicki, M.: Effect of selected simplifications of the unipore model upon the result of the study of the diffusion coefficient in coal. Arch Min Sci 56(4), 859-1276 (2011)

Li, X., Nie, B., Zhang, R., Chi, L.: Experiment of gas diffusion and its diffusion mechanism in coal. Int J Min Sci Technol 22(6), 885-889 (2012)

Wu, Y.-S., Pruess, K., Persoff, P.: Gas flow in porous media with Klinkenberg effects. Transp Porous Med 32, 117-137 (1998) 